\title{
Discurso utópico/distópico regionalista en Un adiós al descontento de Eugenio Mimica
}

\author{
Lorena Patricia López Torres*
}

\begin{abstract}
Resumen
Magallanes se ha provisto a sí misma de una literatura particular y con tintes que la singulariza con respecto a la producción del resto del país. Desde esta posición, haciendo primar las particularidades por sobre la hegemonía que se cierne sobre el continente, la novela de Eugenio Mimica plantea la posibilidad de reinvención del cono sur austral a través de la refundación histórica, política y económica de Magallanes, ya no desde los anales de la historiografía oficial, sino desde su propia conformación como enclave insular y meridional. El atractivo del discurso mimiciano reside en que, en este afán por recuperar la historia particular, se cae en un regionalismo exacerbado y xenofóbico, propio de la condición postmoderna. Este discurso se potencia con el recurso al género utópico que configura la trama de la novela, tras la cual se esconde la verdadera mecánica de la operación escritural: una desoladora mirada distópica de la acabada y decadente realidad magallánica.
\end{abstract}

Palabras clave: utopía/distopía, enclave, frontera, postmodernidad, regionalismo.

\section{Utopian/dystopian regionalist discourse on Un adiós al descontento by Eugenio Mimica}

\begin{abstract}
Magallanes has provided itself a particular literature that makes it unique with regards to the literary production of the rest of the country. From this perspective, taking precedence over the continental hegemony, Eugenio Mimica's novel raises the possibility of reinventing the Southern Cone through a historical, political and economic refounding of Magallanes, not from the official historiography, but from its own formation as insular and southern enclave. The appeal of Mimician discourse lies in its zeal for retrieving a particular story, it falls into an exacerbated and xenophobic regionalism of postmodernity. This discourse is empowered by the use of the utopian genre that shapes the novel, behind which it hides the real the writing process: a bleak dystopian view of the decadent magallean reality.
\end{abstract}

Key words: utopia/dystopia, location, border, postmodernity, regionalism.

* Dra. (C) Instituto de Estudios Latinoamericanos. Freie Universität Berlin.

lorena.lopez.torres@fu-berlin.de 


\section{Introducción}

El escritor Eugenio Mimica Barassi nace en Punta Arenas en 1949; es cuentista, novelista, articulista y cronista. Su obra ha sido incluida en numerosas antologías magallánicas, chilenas y extranjeras y, dentro de las corrientes narrativas que se precisan con relación al campo literario magallánico, su producción se ubica mejor dentro de la llamada narrativa urbana, pero con ciertos guiños hacia las temáticas de la corriente narrativa vernacular, pues su obra abarca desde la problemática de la extinción indígena hasta la caída del gobierno democrático tras el golpe de estado de 1973. Según Óscar Barrientos, la narrativa de Mimica se distingue por: "La exploración de la realidad desde el sitio de lo inesperado (...) que describe personajes intensos dibujados en un Magallanes que comporta diversos estados" (Barrientos 141).

En esta nueva generación que predomina en las décadas de los ' 80 y '90, Mimica se ubica junto a los nombres de Alexis Andrade Dobson, Juan Magal y Juan Mihovilovic entre otros. Esta promoción presenta una marcada depuración del lenguaje narrativo y una notoria asimilación de las técnicas contemporáneas del relato. De este mismo modo se adhieren a corrientes más universales, dejando atrás lo paisajista y localista de la literatura de la corriente vernacular cuyos máximos representantes serían Osvaldo Wegmann y Francisco Coloane. Otra literatura se abre paso para ellos a través de la obra de Cortázar, Quiroga y García Márquez y de la relectura de clásicos como Kafka y Hemingway que exploran la interioridad del hombre, lo que se traduce en una nueva forma de narrar. El escritor magallánico se interna en la problemática del hombre moderno, elaborando una nueva óptica narrativa:

Un cuento patagónico más laberíntico, más internado en lo sicológico y en lo inesperado, despegado de una secuencia lineal, ha venido a surgir recién en las décadas del 70 y del '80 con los más jóvenes, como Mímica, Díaz Eterovic, Juan Mihovilovic, Andrade Dobson, Pablov, Magal y muchos otros (Vega Letelier 9).

La generación que creció y que nació a la vida literaria en los años turbulentos tras el golpe militar, de manera velada da rienda suelta a sus creaciones y esconden sus súplicas en las afónicas sílabas de las palabras vertidas en el papel. La marca del ogro es el nombre con el que Eugenio Mimica llama a la generación conocida como la de los Ochenta o NN. 
El eje central de su novela Un adiós al descontento (1991) gira en torno a un grupo de desadaptados que inician una lucha secreta y silenciosa por lograr la independencia regional del resto del país; plan revolucionario que involucra un cambio de imagen y de mentalidad, recobrando el patrimonio histórico de la meridional zona como baluarte único de identificación y de marcado sesgo separatista del resto de Chile. Esta nueva perspectiva meridional se articula a través de los discursos de los personajes que enarbolan la defensa de la historia magallánica, de los movimientos sindicales, el patrimonio regional, la arquitectura y los emblemas, en un recorrido cronológico y/o sincrónico de aquellos acontecimientos que han marcado a la región ${ }^{1}$.

Mimica contempla al ser humano abandonado a su soledad y autoaislamiento, aún en una ciudad que se precia de acogedora, hospitalaria y cercana. La novela se instala entre la esquizofrenia colectiva y la incertidumbre del mañana en un país militarizado y dialoga con otra obra del mismo autor: la serie de cuentos Enclave para Dislocados (1995) que años más tarde hablará del "encierro momentáneo e inspirador, media figura entre tranquilidad y bullicio..." (Mimica s/p) que se percibe en la coexistencia del habitante y la ciudad.

\section{Utopía regionalista: la fundación de Meridionía}

A través de la obra de Eugenio Mimica Un adiós al descontento, es posible leer la utopía regionalista que re-emerge en Magallanes como la necesidad de sus habitantes de refundar a la alejada ciudad de Punta Arenas como la capital de una nueva nación: Meridionía. Esta idea se establece a partir de su historia local (Mignolo 2003), de su identificación y caracterización como enclave, de-limitado por linderos fronterizos tanto estáticos como dinámicos (Urbina 1983) que le dan conformidad de epicentro cultural y patrimonial aislado e independiente en relación con el resto del país.

En la definición de Mignolo (2003), esta historia local se expresa a través de resituar el pensamiento fronterizo en la intersección de las historias locales y los diseños globales a partir de la materialización de la perspectiva subalterna, denunciándose así el hecho de cómo los diseños

$1 \quad$ A modo de ejemplo, la madrugada del 27 de julio de 1920 se desata en Punta Arenas una ola de terror, vandalismo y destrucción: "Los guardias blancos atacan y queman el local de la Federación Obrera de Magallanes, asesinando, torturando y vejando a trabajadores y familiares que se encontraban afiliados a la organización obrera". Nunca se pudo establecer responsabilidades de ningún tipo, ya que, como tantas veces sucede, se contó con la complicidad de jueces y policías que alargaron indefinidamente el proceso, en el que nadie recibió castigo alguno (Cárdenas y Vega 1). 
globales se ven impulsados por el deseo de homogeneidad y la necesidad de hegemonía. Únicamente a través de la diversidad como proyecto universal podemos imaginar alternativas al universalismo.

De ahí deriva la hipótesis que se plantea inicialmente en el título de este artículo, pues, a partir de una lectura utópica /distópica de la obra de Mimica, se perfila el cariz regionalista que caracteriza a Magallanes haciendo hincapié en su constitución de territorio aislado y en el componente histórico que la atraviesa, configurando la identidad del hombre magallánico.

Este acentuado regionalismo magallánico que se observa en la novela no sólo apunta a un revivalismo de las tradiciones sino que es el intento de los personajes por re-fundar Magallanes llevando a cabo una acción separatista. Este acto en particular encuentra fuerza y significado en el discurso de los personajes que apelan a las características geográficas del territorio -en especial su insondable aislamiento-y propiamente a la historia magallánica -la cual no siempre ha sido incluida en la filas de la historiografía nacional- como antecedentes que configuran la particular convivencia entre la zona y su habitante, generándose así una complicidad entre ambos con dirección hacia un mismo derrotero.

Ahora bien, este discurso utópico posee sus caracteres particulares, los cuales se evidencian en la novela y que permiten entender la funcionalidad del discurso del narrador y de los personajes, en cuanto a su intencionalidad prospectiva y desiderativa, así como la pretensión que el escritor tiene acerca del futuro de la sociedad en la que vive: lo que podría ser².

Este preámbulo nos permite introducir además el planteamiento postmodernista que conlleva esta hipótesis, y que se refleja en la reafirmación de "la autonomía de lo parcial frente a la hegemonía del todo" (Schultz 92), el cual recupera y reivindica identidades regionalistas y tradiciones de la inercia, pero se infiere que en ese salvaguardar del patrimonio se revela cierta actitud xenofóbica que muestra ese sesgo separatista, individualista y de autenticidad que alimenta la utopía y que se hace presente en el discurso mimiciano.

Esta afinidad del habitante/cuidadano magallánico con su tierra manifestada en la novela resulta ciertamente difícil de explicar. El solo hecho de hablar de identidad hoy en día es un asunto por lo demás

2 La utopía, como construcción ficcional de la sociedad, aparece en las obras La República de Platón; Utopía de Tomás Moro y Nueva Atlántida de Francis Bacon. Entrando en este juego de homologaciones, se ubica en menor escala esta novela de Eugenio Mímica (N. de la A.). 
complejo, pero lo que se desprende del discurso mimiciano es que, frente al embate de una postmodernidad arrolladora que bombardea al ser humano con un sinfín de historias que se suceden vertiginosas y con nuevos modelos de vida que se trasponen simultáneamente, el problema de la identidad en Magallanes sigue siendo una constante preocupación desde el punto de vista sociológico y cultural. Se advierte en el habitante una mayor atención a su propio relato y a su propio devenir histórico. Tal vez de esa manera se entienda el discurso regionalista que levantan los revolucionarios de Un adiós al descontento; de ahí que el recurso a la utopía les permita articular una posible Nación, la misma que circula en el territorio como leyenda urbana.

A través de esta instancia de recuperación de la identidad local que se entroniza en la región, se pretende cambiar "la idea de una perspectiva única para el conocimiento y la verdad, esta última es cuestionada para ceder en favor de las verdades parciales" (Schultz 92). Esto quiere decir que nos encontramos con un regionalismo que se abre paso para mostrar una verdad parcial, lateral o periférica desde el confín austral de una América Latina que se debate entre la modernidad y la postmodernidad, en una suerte de movimiento pendular en lo que la autora señala como el replanteo del eje norte/sur periferia/centro. De esta forma, se hace latente la esencia utópica de América y del arte en cuanto a sus intervenciones en el proceso de emancipación social. Es así cómo "la utopía se corresponde con el Metarrelato, donde según la estructura pendular, el contenido semántico de la utopía representa los extremos: se cree en ella o se niega como sistema que sacrifica la sociedad de hoy en función de la emancipación de una supuesta sociedad futura" (Schultz 96).

Esta utopía, de la que aparentemente se hace necesario prescindir por el bien del progreso americano, se asienta en las raíces de las naciones y de sus pueblos como herramienta que permite recuperar aquellas tradiciones con la significación que las caracteriza dentro de su entorno propio. La novela de Mímica es una obra que verbaliza la reivindicación de una identidad que corre y toma cuerpo en el entramado de acontecimientos históricos trascendentales, específicamente desde el hito descubridor y más tarde el fundacional de la primera ciudad en la Región de Magallanes, sucesos que de alguna forma han sido relegados a magros datos historiográficos. De acuerdo con esta realidad, "el pensamiento fronterizo sería precisamente el del rumor de los desheredados de la modernidad, aquellos para quienes sus experiencias y sus memorias corresponden a la otra mitad de la modernidad, esto es, a la colonialidad" (Mignolo 27). 
Una vez que se toma conciencia de la esencia local, la utopía persiste en el retorno a ese estado mejor transformándolo en una visión del futuro mejorada y revitalizada. Por lo tanto, esta mirada utópica no ha de perecer debido a los avances que involucran al mundo moderno, pues en este sustrato austral esa utopía permanece vigente ya que es la que anuda el lazo atávico del hombre con su tierra, siendo por lo mismo portadora de la identidad del habitante como magallánico.

De esa manera, la novela se aboca al rescate de la identidad magallánica, su historia fundacional y su periodo de mayor auge en sus primeros años de vida, en una suerte de refundación de la región como un nuevo país, articulándose o proyectándose desde el presente hacia un futuro en el que Magallanes amalgama ese pasado nostálgico con los avances tecnológicos, el desarrollo económico y la independencia política que hasta entonces se le ha negado, en un contexto postmoderno de revivalismo de la tradición ${ }^{3}$.

La novela es una excelente muestra de la narrativa magallánica de finales del siglo XX que habla desde la marginalidad y el autoconocimiento, donde el narrador se entroniza como voz del aislamiento no sólo geográfico -que es natural- sino también social, político, económico y cultural en el que se encuentra la región y sus habitantes. Desde ahí el escritor magallánico interactúa literariamente con su tierra y sus pares, entendiéndose con códigos propios y comprendiendo la problemática de la zona y de sus habitantes.

En la articulación de la nación independiente, Emilio, el líder del insurgente grupo, debe seguir los pasos lógicos que indiquen el nacimiento de la Nueva Patria. Lo primero es diseñar la bandera, que, como ya lo había previsto, sigue los patrones de aquellas enarboladas por otros países emergentes en el mundo; una vez confeccionada en papel se la enseña a sus correligionarios:

Era una enseña dividida matemáticamente en cinco campos horizontales, con el color azul ocupando el superior y el inferior, luego el amarillo llenando los espacios siguientes en igual proporción, quedando un campo central que era cubierto por el rojo... una bandera tricolor, porque en cierta ocasión había leído que ese era el emblema de todas las nacionalidades nacientes (claro, consecuencia de la Revolución Francesa,

3 El post del postmodernismo alude a: dualidad, alusiones, plurivalencia de los signos, equivalencia valórica historicista, recuperación revivalista, búsqueda neo-vernácula (un regionalismo revivalista) (Schultz 102). 
acotó al punto Luciano Calhuante, que dominaba esos temas históricos como ningún otro) (Mimica 55).

El hombre meridionés de Un adiós al descontento es la cara visible del orgullo pionero en el Estrecho, situando a los colonos fundadores y sus logros como un ejemplo de entereza y sacrificio. Como heredero de esa abnegación para con la región, el meridionés ha de instaurar una nueva comarca con un futuro prometedor que honre a sus antepasados, pero que al mismo tiempo renueve su compromiso ciudadano con Meridionía. Ésta suele ser la conversación inicial que el Brujo -compañero revolucionario- establece en cada reunión, con el pretexto de concientizar al resto de sus camaradas:

...salían a relucir todos los adelantos técnicos y humanos logrados antes en Meridionía, desde la primera planta térmica hasta los pasos iniciales del sindicalismo, desde la cinematografía hasta las huelgas laborales....El Brujo recalcaba que siempre los meridioneses habían sido pioneros, iniciadores, fundadores... (Mimica 91).

\section{Conceptos de frontera y enclave en la periferia meridional}

Siguiendo las investigaciones de Urbina (1983) podríamos reconocer históricamente a Magallanes como una suerte de enclave cultural y militar marcado por el aislamiento, el que expresa una necesidad geopolítica de conservación territorial, manifestándose en la época contemporánea a través de una visión intramuros autovalidada interiormente. Esta necesidad de conservación territorial determina el concepto de cultura como una forma integral de vida creada histórica y socialmente por una comunidad, de acuerdo con la forma en que resuelve o entabla relaciones con la naturaleza, con sus pares, con los de otras latitudes y con el ámbito de lo sobrenatural, a fin de dar continuidad y sentido a la totalidad de su existencia, mediante una tradición que sustenta su identidad, dándole conformidad de enclave cultural.

En cuanto a enclave militar, Magallanes fue percibida -primero por el español y posteriormente por los colonos- como un asentamiento estratégico de carácter carcelario y militar. Las primeras ciudades fundadas dan cuenta de ello; éstas debían posicionarse como primera avanzada para una colonización del continente desde el extremo sur y de la misma manera operar como estructuras de defensa del territorio contra 
la arremetida inglesa. El gobierno chileno seguirá privilegiando esta particularidad y Magallanes seguirá siendo considerada como presidio, una réplica de la Siberia rusa4.

Este aislamiento al que remite nos hace pensar en una visión desde afuera que se tiene de Magallanes -tanto desde el extranjero como del resto de la nación-que implica necesariamente una visión desde adentro. Cuando digo desde adentro o desde el interior (López 74), me refiero a la toma de conciencia en el hombre magallánico acerca de lo que significa vivir en esta tierra y lo que ésta aporta como sustrato a su identidad. La concientización de ser magallánico provoca en sus habitantes el retorno a sus raíces como único lazo identitario, se expresa con mayor profundidad y vive en aquellos símbolos que unen al pueblo magallánico, a este país al sur de Chile. En este aislamiento, la región se advierte ajena a una realidad que involucra a Chile en su totalidad, pues no se considera partícipe de las disposiciones políticas que la afectan directamente, que devalúan lo propio y que generalizan particularidades para todo un país ${ }^{5}$.

La vida en esta zona es del tipo de frontera. Esta se define como una zona de "espacios ilimites abiertos a las avanzadas colonizadoras que marchan y presionan sobre territorios vírgenes" (Urbina 16). El concepto de frontera se entiende igualmente como un espacio de interacción, que obedece a un proceso o situación compleja. Puede referirse a una línea arbitraria trazada sobre un territorio o a un accidente geográfico que opera como valla, pero también puede señalar la existencia de un pueblo marginado dentro de una sociedad organizada o designar el desplazamiento de un pueblo agresivo sobre otro medianamente calificado para defenderse $e^{6}$.

4 En 1584 el español Pedro Sarmiento de Gamboa funda dos ciudades en las costas del Estrecho de Magallanes: Nombre de Jesús y Rey Felipe. Abandonados por la corona española y ante la ausencia de Sarmiento capturado por corsarios ingleses, sus primeros habitantes perecen sin comida ni resguardo. La ciudad-metropoli Rey Felipe hoy se conoce como Puerto del Hambre bautizada así por Thomas Canvendish y recuerda el intento colonizador más cruento de la historia de Magallanes (López 31). En 1843 se construirá Fuerte Bulnes en las inmediaciones del antiguo emplazamiento confirmando tal posición, extendiéndose a la fundación de Punta Arenas en 1848 y a otro punto insular estratégico utilizado como lugar de confinamiento durante la dictadura militar, la isla Dawson (N. de la A.)

5 El 12 de enero de 2011 se declaró una huelga de carácter regional que suspendió completamente las actividades en todo el territorio; ésta tenía como motivo protestar ante la súbita alza de un 16,8\% en el precio del gas exclusivamente para Magallanes. Como argumento el Gobierno señaló que la región era "una zona privilegiada" y que por lo tanto su deber era contribuir con el bienestar de la nación entera. Las declaraciones de los ciudadanos magallánicos no se hicieron esperar a la hora de aclarar lo que significa el "privilegio" de vivir en "la RIM (República Independiente de Magallanes)". (Carta del ciudadano Arturo Díaz que circuló en Facebook). Para mayores antecedentes revisar el periódico digital El Pinguino de Magallanes (N. de la A.).

6 En la época colonial, todo el Reino de Chile se comporta cual frontera, pero tradicionalmente 
El concepto de frontera se enlaza con la visión intramuros para plantear la situación de ubicación periférica. La vida dentro de los límites de la región meridional da muestras de un desarrollo que avanza a "un ritmo histórico distinto del de los centros nucleares de Chile" (Urbina 16), incomunicada con el resto del país y validada por su condición de extremo sur solitario y olvidado, "condicionado por una geografía que hace que estas tierras se comporten como lugar de destierro" (Urbina 16) ${ }^{7}$.

El hombre fronterizo, pionero y colono a la vez, va desbrozando caminos y preparando el dominio mediante la guerra, el desmonte, la explotación forestal y ganadera, la agricultura, el comercio, que en Magallanes se homologa con el genocidio indígena, la explotación aurífera y ganadera, las labores petrolíferas y de ultramar.

\section{El género utópico clásico en el diseño de Meridionía}

A través de este reencuentro del hombre y el mito, América Latina reinicia el retorno a la época en que se sitúan las utopías; el continente se rehúsa a renunciar a su carácter mitológico y/o ancestral y, de alguna manera, busca escapatoria a la condición (post) moderna por medio de una compenetración con su cosmogonía utópica: "visión nostálgica de un tiempo sin historia y de un espacio de donde se ha abolido toda evolución nefasta" (Ainsa 42).

Ovservando a Magallanes desde esta perspectiva, es posible reconocer en la novela ciertos caracteres del género utópico que revelan el deseo particular del autor por perfilar a la región bajo la denominación utópica de enclave, isla, planeta o castillo, casi en un ostracismo voluntario. Es, en palabras de Ainsa, "una clausura horrible o consoladora" (93) en la que Mimica sitúa a la nueva región Meridionía y su capital Césares.

El primer carácter del género utópico que se introduce en la narración es el que apunta a la insularidad, pues la representación geográfica de la utopía en un espacio aislado es esencial (Ainsa 41). A partir de la obra del británico Moro, se enfatiza la insularidad como ficción geográfica por medio de la cual se pretende preservar una comunidad de la corrupción del mundo exterior, al mismo tiempo que se presenta un

se la ubica a la altura del Bío-Bío, que separa al Chile colonizado del pueblo mapuche, esta es la frontera de guerra viva (Urbina 16).

7 A comienzos del siglo XX, Magallanes era ya una región consolidada, pese a que el resto del país sigue considerándola colonia: "Aquello del Territorio de Colonización... justificado en un momento, había perdido su razón de ser y más daba la sensación de ser símbolo o expresión de una marginalidad político-geográfica" (Martinic 106-107). 
mundo cerrado, cosmos miniaturizado regido por leyes específicas que escapan al magnetismo de lo real.

La insularidad de Magallanes se expresa en la imagen cartográfica de la porción de tierra rodeada de agua: el Estrecho de Magallanes la circunda por el sur y por el este; hacia el norte se encuentra con el seno Otway y hacia el oeste la rodea una seguidilla de fiordos y canales de difícil acceso. Avanzando aún más hacia el norte, los glaciares del Campo de Hielo Sur son un poderoso impedimento de contacto vía terrestre con el resto del territorio nacional. El estrecho es -hasta avanzado el siglo XX- el paso interoceánico que facilita la llegada de viajeros de todo el mundo y que permite la colonización de Meridionía y su posicionamiento como enclave austral ${ }^{8}$.

Pero ciertamente hay espacios que, insertados fuera de la tradición del género, se insularizan por lo aislados que se observan; un ejemplo es la casa del protagonista, que actúa como reducto que garantiza a través de la distancia el espacio ideal de la utopía. En la novela, el departamento de Emilio y su esposa Francisca es el lugar indicado para dar rienda suelta a la organización del plan revolucionario. Es allí donde se reúnen por primera vez a imaginar Meridionía: “...se reunieron todos en el departamento de los Trinalba Lunares en su primera sesión de trabajo y comunión idealista. Esa vez elevaron su acta, apelando a toda la ceremonia y emotividad que el caso aconsejaba, de lo que dieron en llamar Asamblea Constituyente por la Independencia de Meridionía" (Mimica 51).

Uno de los topos más recurrentes en el pensamiento utópico es el de la Ciudad Ideal, es decir, la planificación urbanística. La ciudad real con todos sus males, muchos de ellos sin remedio, se enfrenta a la metrópoli proyectada como una estructura urbana regular y geométricamente prevista. Todo proyecto de ciudad ideal tiene una significación ideológica, porque fijar los límites urbanos condiciona al otro y condiciona la forma de gobierno; éste es el "sueño de todo gobernante que espera asegurarse el poder y la autoridad sobre sus súbditos” (Ainsa 43). Así se entiende que la construcción de la utopía oscile entre la visión urbano-espacial y la

8 Un primer hito importante es el descubrimiento del estrecho por Hernando de Magallanes en 1520 , acontecimiento decisivo para investigadores y escritores regionales como primera exploración y reconocimiento del país desde estas postrimerías como señalaría Osvaldo Wegmann: "La conquista de Chile comenzó por el sur" (15). Esta frase ya es concluyente para muchos en cuanto a la importancia que representa Magallanes para la historia de Chile y el mundo, tierra hasta entonces ignota a la que se le ha negado un lugar de importancia en sus páginas (López 22). 
puramente social, ofreciendo en su mayoría una mixtura de ambas. Desde la aparición de la obra de Moro, no es de extrañar que la planificación urbana acompañe a la utopía; ejemplo americano es el damero -tablero de ajedrez- de los planos fundacionales de las urbes americanas en la época colonial. El símbolo utópico de la ciudad ordenada es reiterativo para el autor, pues la constante está en contrastar la sociedad en la que se vive con aquella en la que se desea vivir.

En tono alegórico, Mimica describe una ciudad sumida en la opresión de un gobierno militar. Los personajes hurgan en su historia personal para confeccionar un provenir único, auténtico y alejado de las maquinaciones y los ultrajes. El autor ya no configura a Punta Arenas/Césares como la otrora colonia española; en la ficción, esta nueva región es un espacio territorial y geográfico bien organizado y limpio, donde cada detalle ha sido cuidadosamente pensado y estudiado, que ostenta una construcción arquitectónica que no tiene nada que envidiarle a Administrativa ${ }^{9}$ o al resto del mundo:

Una capital que tendría un ordenado conjunto de viviendas, edificios y parques con arboledas y fuentes de agua, paseos peatonales bajo cúpulas de vidrio que impidieran los ataques agrestes del clima, enormes escenarios deportivos (donde pudieran presentarse los mejores circos del mundo, me murmuró Emilio una vez), galerías de arte, museos y centros de recreación familiar, pero que no poseería calles. El diseño lo había centrado en función a las áreas verdes, dando lugar a pequeños barrios o vecindades. Habría algunos destinados exclusivamente a la vida hogareña, mientras que otros congregarían a escuelas, iglesias, clínicas, comercio, oficinas públicas, banca, hotelería y la administración gubernamental, quedando todo cerca de todo (Mimica 73).

Unido a lo anterior y con respecto a la armonía, el carácter de reglamentación en la ciudad actúa como referente al colectivismo homogeneizador de la vida, el trabajo y la organización del ocio de los habitantes de la Ciudad Ideal, dividida en barrios precisos. Al respecto, Ainsa señala que: "La condición reglamentaria fija el dirigismo de los gobiernos, generalmente autoritarios y subraya la condición pedagógica del texto, presentado como un modelo a seguir. La utopía es totalizante en la medida en que intenta organizar la armonía social a través de una teoría integral en la cual están previstos todos los aspectos de la vida colectiva y privada" (44).

9 Nombre con el cual los revolucionarios llaman al resto del país, y en especial, a su capital. (N. de la A.). 
En este orden, para los revolucionarios liderados por Emilio, todos los meridionenses deben vivir en iguales condiciones como el único medio posible para alcanzar una nación de equidad e independencia; el grupo disidente persigue el reconocimiento de cada individuo como ciudadano activo y partícipe de su propio desarrollo y progreso:

Con cierta uniformidad arquitectónica se lograría un paso importante en el campo social, pues no existirían las barriadas pobres y marginales. Cada cesarense tendría un trabajo estable para vivir decentemente, ya que todo sería parte de un todo armónico. Así, sin pobreza, se eliminaría la delincuencia por causas económicas. No habría, por lo tanto, diferencia de clases, salvo la que otorgara el grado de conocimiento, la inteligencia y empeño por ser cada vez mejor. La policía de Césares sería la menos activa de la tierra, casi una excentricidad, reliquia para nostálgicos de la vida pasada (Mimica 74).

El tipo de reglas o planificación de sociedad que desean forjar Emilio y sus secuaces escapa a la racionalidad de un planteamiento utópico que se reconozca como ordenado o legislado; obedece, más bien, al sentimiento de erradicación de los males que, como señala el protagonista, amenazan la consolidación del proyecto de Meridionía y del hombre nuevo que lo ha de habitar. Para ello plantean la creación de un espacio singular:

...el cementerio de los malos hábitos, espacio desolado donde la gente pudiera ir sola o en romeros a sepultar alguna envidia, una arrogancia, una irresponsabilidad, un atisbo de injusticia o una cierta deslealtad, a manera de arrepentimiento y penitencia (Mimica 72).

\section{Excesos amargos: el mundo al revés en la cámara}

Al parecer, el agotamiento físico y moral del grupo va mermando el ideario libertador y de unión para Meridionía.

Existe un elemento subterfugio que descompone o muta el carácter utópico y redentor que tanto el autor empírico como el narrador han defendido a través de las páginas de la novela. Meridionía se convierte en un estructural modelo de ciudad estática y fija, que, en el deseo de sus libertarios por socorrerla y salvaguardarla de mezquindades y desavenencias pasadas, se estanca en una planificación rigurosa y sometida a nuevas normas y opresiones igualmente sancionadoras que las de antaño. Con Ainsa coincidimos en que, "en la recuperación antropoló- 
gica de expresiones utópicas de todo tipo, no debe olvidarse el aspecto negativo implícito en la utopización excesiva, aspecto que es necesario subrayar en el ámbito americano, tan proclive como ha sido a confundir "deseos con realidades" y a confiar excesivamente en providencialismos y marxismos de toda clase" (61).

La novela, finalmente, se entiende como una crítica negativa y destructiva, una distopía que deja en claro que el modelo utópico entra en crisis por la constatación pesimista de que el hombre por naturaleza es malvado. "De aquí nace la imposibilidad de un proyecto utópico, y la amarga constatación, de que el mundo otro no es otra cosa que la copia especular y deformada del mundo en el cual se originó. No existe ninguna posibilidad de un mundo alternativo, porque el hombre no puede cambiar" (Fortunati 37-38).

La distopía entonces se reconoce en constante pugna y/o diálogo con la utopía y al mismo tiempo la parodia invirtiendo las ideas-imágenes ${ }^{10}$ con las que trabaja la imaginación utópica de los personajes. Esta característica llamada mundo al revés plantea que sobre su base "existe una metáfora visual implícita o explícita que sugiere la idea de mirar el mundo a través de un instrumento óptico que integra y potencia el ojo humano, develando una serie de mundos y perspectivas impensadas" (Fortunati 34-35) ${ }^{11}$.

La dimensión distópica es finalmente aplicable al entrecruce textual y formal que hace Mímica en Un adiós al descontento. Un ejemplo de este recurso se presenta en la novela desde el comienzo, que evidentemente prefigura el final de la hazaña meridionesa. Esta primera aproximación, una suerte de retrosalto hacia el origen de la narración, indica una visión invertida en lo que Emilio manifiesta como el abanderamiento por su causa. Este cauce emancipador alcanza al narrador, René, quien ya advierte que la lucha de su amigo está inminentemente perdida. En este momento de la narración el mundo al revés se expresa por medio de la máquina fotográfica, recurso visual a través del cual Emilio capta todo lo que le es significativo y beneficioso para sus propósitos, proporcionándole solidez y forma a sus ideales y proyectos.

10 La bandera es una de las imágenes más representativa del movimiento, es la cara visible de la realidad otra que se intenta consolidar (N. de la A.).

11 La hipótesis del mundo al revés surge en el 600 DC año en el que se realiza una serie de adelantos científicos de importancia como el telescopio, el microscopio y las habitaciones catóptricas con espejos multiplicados o curvados que alteran la apariencia real (Fortunati 35). 
Ad portas a que el narrador comience el relato de lo vivido por el grupo independentista, la idea-imagen ya invertida de la utopía abre paso al periplo en decadencia del sueño regionalista:

Tengo frente a mí una tarjeta postal que muestra un trozo de cielo libre de nubarrones y esa bandera con dos franjas azules, dos gualdas y una roja, flameando al viento. Al reverso dice estamos bien, aunque extrañamos algo nuestro entorno familiar, saludos a todos los meridioneses que pregunten por nosotros, Emilio y Francisca. Me quedo pensativo mirando la fotografía de esa postal, a pesar de conocerla y haberla visto antes por docenas, y vuelvo a leerla observando atento los trazos que forman cada letra (Mímica 7).

La imagen fotográfica proporciona a la narración información necesaria para comprender la génesis del plan de independencia al cual se abocaron, imagen que el narrador contempla absorto tomando distancia de los acontecimientos sucedidos y de sus protagonistas:

Un asomo al que muy pocos fueron llamados a participar y tuvieron acceso, para trabajar y convertir el proyecto en realidad (así lo decidimos desde un principio, por razones de precaución, me señaló Luciano Brujo Calhuante). Entonces vuelvo a mirar la postal y me quedo largo rato ensimismado en esa imagen captada por la lente de Emilio, en un montaje que hizo para apoyar la difusión de las ideas independentistas (Mimica 8).

Existe un dejo de alteridad en la utopía meridionesa, en donde se aprecia cierta fragmentación o grietas en la presunta unidad de forma y contenido, "inmanencia no armonizada a través de la cual se revelan las significaciones estético-utópicas de lo que no es-todavía” (Ainsa 59-60).

Un adiós al descontento se aproxima al desenlace -luego de una lectura optimista de sus páginas- a un desmoronamiento de sus cimientos. En este punto esa "no existencia" a la que se refiere Ainsa deja entrever que el tan ansiado proyecto no es más que eso, y que la nación independiente como ideal, imagen o sueño utópico, se desmorona ante la realidad aparente de una vuelta al orden que ejecuta el gobierno central, el mismo al que habían dado la espalda en el encierro "consolador" de su quimera. El descontento en el que viven sus compatriotas no alcanza a ser erradicado por el entusiasmo independentista que mantuvo al grupo a flote durante tanto tiempo; en ese momento se retorna a la realidad de la sociedad en la que viven. 
En el afán por realizar este revivalismo regionalista y proyectar una realidad paralela y deseada por el autor y, por qué no decirlo, por el lector; la utopía meridionense resultante es la combinación de un "pesimismo y un cierto realismo", porque el optimismo, aunque parezca revolucionario, es "un veneno tan grave como el pesimismo absoluto" (Ainsa 62). Es decir, en la intención de imponer una utopía, no se puede perder de vista que ésta, por más irrisoria y poco factible que sea, es fecunda en su capacidad de crear posibilidades, aunque los resultados sean inesperados o desmoralizantes.

\section{A modo de conclusión}

La novela de Eugenio Mimica confronta la realidad con una construcción paródica de la historia fundacional de Magallanes a través de esta suerte de renacimiento de la región bajo nuevas regulaciones y leyes por medio de las cuales vuelve a quedar a merced del control hegemónico de unos pocos y donde el enjambre de habitantes es puesto en orden bajo los parámetros de la homogeneidad establecida.

Es esta una tensión entre el pasado que se fue, pero que quiere volver a reinar y el futuro que es más bien incierto el que actúa como el motor que impulsa la hazaña independentista de ese grupo de amigos. Luchan con la convicción de que la dinámica de la sociedad y del libre pensamiento les abrirá otra vez las puertas a una proyección de una renovada Magallanes/Meridionía como enclave territorial emancipado.

Ni la lejana Magallanes anclada en el corazón de la Patagonia ha escapado a los avatares de la sociedad (post)moderna y su literatura se ha encargado de hacerlo visible en múltiples oportunidades. No es menor el alcance de la aparición de otra obra posterior de Mimica titulada Enclave para dislocados (1995) un conjunto de relatos breves en que se manifiestan las diferentes realidades que vive el hombre magallánico al borde del cambio de siglo, con los conflictos político-económicos y las falacias que estas transformaciones conllevan.

Un adiós al descontento enfatiza el regionalismo y el discurso utópico y su distopía posterior, pero no deja de ser trascendental que en el relato se pongan en discusión estas problemáticas así como también la noción de identidad, sobre todo pensando que se hace desde las orillas de un siglo XX que pareciera haber superado estas inquietudes. La identidad en relación a la configuración de Magallanes debe ser considerada como un asunto de peso para su historia y conformación como enclave periférico 
y tal vez por ello sea necesario articular otros soportes que permitan su tratamiento, a través de los cuales sea posible hablar de construcciones o discursos identitarios.

En la transición de los siglos XX y XXI los escritores de la región están haciendo el intento por generar estos nuevos dispositivos para una mejor comprensión de la realidad magallánica, lo que significa ofrecer una alternativa a una idea de identidad que no parezca encerrada en sí misma ni mucho menos inamovible.

El análisis de la obra de Eugenio Mimica implica un diálogo y una coexistencia con la obra de otros narradores magallánicos. Mientras el autor construye Meridionía como la alternativa modelada de Magallanes en la imaginación, otros escritores regionales se muestran igualmente involucrados en escudriñar esta posibilidad.

Entre estos últimos se encuentran el narrador Óscar Barrientos, quien re-escribe utópicamente a Magallanes -como una legendaria nación perdida en el confín del mundo-, jugando con los elementos de la naturaleza y la geografía dispar de la zona, pero haciendo uso de una idea primordial de "imaginación" en que la literatura magallánica nunca se había situado del todo. A esta tendencia se adhieren El diccionario de las veletas y otros relatos portuarios (2003), Cuentos para murciélagos tristes (2004), Remoto navio con forma de ciudad (2006) y su última publicación titulada El viento es un país que se fue (2009). La narrativa que surge alrededor del mítico Puerto Peregrino de sus obras se adhiere a la imaginería y al discurso utópico donde el relato fundacional y la relación del habitante con la geografía austral están mediadas por la idea de un posible origen mítico, lo que de alguna manera explicaría tan estrechos vínculos.

Pavel Oyarzún, más conocido por su obra poética con títulos como La jauría desquiciada (1993) y Patagonia: la memoria y el viento (1999), publica durante la primera década del siglo XXI una trilogía narrativa que acaba de cerrarse con la aparición de la novela Barragán (2009). El hilo conductor de su narrativa es la exploración de la historia fundacional de Magallanes, pero a través de hechos marginales incluso para la historiografía regional. De esta manera, aparece en su novela El paso del Diablo (2004) la historia del huelguista -el gallego Antonio- quien escapa a la muerte en manos del 10 de Caballería; en San Román de la Llanura (2006) el estanciero Maximiliano Meléndez busca quién escriba sus memorias como Rey de la Patagonia, mientras que el tehuelche Felipe Barragán es rescatado del olvido a partir de una vieja fotografía. Forman igualmente una trilogía donde otros son los protagonistas de momentos 
históricos clave para la región; es un cambio de ángulo de la mirada que recoge los hechos: son los que mueven la revolución obrera, los que develan el verdadero rostro de la colonización y los que se niegan a ser expulsados de sus tierras.

El mismo Mimica se aleja de los contornos puramente ficcionales y escribe una novela sobre el mundo del petróleo titulada Tierra del Fuego en días de viento ausente (2004), sin duda alguna, una obra que recupera el pasado próspero de la belle époque de Magallanes, momento histórico que no deja de inquietar a los creadores; de esta manera los escritores van y vuelven entre lo que es y lo que en la imaginación representa esta porción de tierra.

Finalmente, en la utopía regionalista de Eugenio Mimica, la búsqueda se centra en la capacidad de reconocernos a nosotros mismos como constructores revolucionarios de nuestros anhelos; cuando la distopía en la que yace Meridionía sea revertida y relegada, ese será el momento en que digamos adiós... al descontento.

\section{Bibliografía}

Ainsa, Fernando. Necesidad de la utopía. Montevideo: Tupac Ediciones, 1990.

Barrientos, Óscar. "Corazas de hielo gruñen en el Fondo de los Fiordos. Revisión crítica de la Nueva Literatura Magallánica". Pluvial. Revista de literatura y humanidades 2: 136-142, 2001.

Cárdenas, René y Vega, Carlos 1990. "La Masacre de la Federación Obrera de Magallanes". Impactos Digital No 10 (11 de noviembre de 2006). (http://www.surdelsurpatagonia.com).

Fortunati, Vita. "Las formas literarias de la antiutopía". Paesi di cuccagna e mondi alla rovescia. Florencia: Alinea, 1989. 33-44.

Fugellie, Silvestre. Magallanes en la Edad del Oro. Punta Arenas: Editorial Atelí, S. A., 2002.

López, Lorena. Narrativa Vernacular y Narrativa Urbana: Tradición y ruptura en la configuración del universo literario magallánico (Tesis Licenciatura). Valdivia: Universidad Austral de Chile, 2005.

Martinic, Mateo. Historia de la Región de Magallanes. Punta Arenas: Ediciones de la Universidad de Magallanes, 1977. 
Mignolo, Walter. Historias locales/Diseños globales. Colonialidad, conocimientos subalternos y pensamiento fronterizo. Madrid: Ediciones Akal, S. A., 2003.

Mimica, Eugenio. Un adiós al descontento. Santiago: Mosquito Editores, 1991.

Schultz, Margarita. "Relación entre estética y filosofía en el ámbito de la postmodernidad". Postmodernidad y Postcolonialidad: Breves reflexiones sobre Latinoamérica. España: Vervuert, Iberoamericana, 1997. 90-103.

Urbina, Rodolfo. La periferia meridional indiana. Chiloé en el siglo XVIII. Valparaíso: Ediciones Universitarias de Valparaíso, Universidad de Valparaíso, 1983.

Vega Letelier, Carlos. "Suplemento Literario". La Prensa Austral 9: 1, 1987.

Wegmann, Osvaldo. Magallanes Histórico. Punta Arenas: Indus. Hersaprint. 1983. 